\title{
Alunos percorrem as histórias narradas na cidade através do game Pokémon GO
}

\author{
Márcia Elisa Teté Ramos* \\ Arnaldo Martin Szlachta Junior ${ }^{\dagger}$
}

\begin{abstract}
RESUMO
O propósito deste texto é o de descrever uma pesquisa realizada com alunos do Ensino Médio de uma escola pública de Maringá, Paraná. Destacamos no momento nossa análise sobre as ideias destes alunos em relação à (sua) cidade, obtidas por intermédio do aplicativo game Pokémon GO. Aproveitando-se da tecnologia de realidade aumentada (justaposição entre virtual e real), os alunos puderam percorrer a cidade para encontrar e refletir sobre alguns lugares, objetos ou imagens em que determinada história é contada. A atividade se desenvolveu conforme a ideia de aula-oficina de Isabel Barca (2004) articulada com a matriz disciplinar de Rüsen (2001). Os alunos construíram narrativas escritas decorrentes desta atividade, e são estas narrativas que transformamos em ideias-síntese.
\end{abstract}

Palavras-chave: Pokémon GO. Ensino de História. Cibercultura. Ideias históricas. História da cidade.

\section{Students walk through the stories narrated in the city through the game Pokémon GO}

\begin{abstract}
This paper proposes to present a research carried out with high school students from a public school in Maringa, Parana, Brazil. We highlight at the moment our analysis on the ideas of these students in relation to the city (their hometown), obtained through the game application Pokemon GO. Taking advantage of the technology of amplified reality (juxtaposition between virtual and real), the students were able to walk through the city to find and reflect on some places, objects or images in which a certain story is told. The activity was developed according to the theoretical proposal of Isabel Barca's "aula-oficina" (2004) articulated with the disciplinary matrix of Rüsen (2001). The students constructed written narratives resulting from this activity, and these narratives are the material that we transform into synthesized ideas.
\end{abstract}

Keywords: Pokemon GO. Teaching History. Cyberculture. Historical ideas. City history.

Artigo recebido em 25 jul. 2018.

Aprovado em 14 abr. 2019.

\footnotetext{
* Docente do curso de graduação em História, docente e Coordenadora do Mestrado Profissional em Ensino de História da Universidade Estadual de Maringá; docente do Mestrado em História Social da Universidade Estadual de Londrina. Doutorado em História da Educação na UFPR e pós-doutorado em Educação na USP. E-mail: mtete@uel.br.

† Docente do curso de História da Universidade Estadual de Maringá. Mestrado em História Social na Universidade Estadual de Londrina e doutorado em História na Universidade Estadual de Maringá. E-mail: arnaldosz@gmail.com.
} 


\title{
A cidade: múltiplas possibilidades de ensino
}

\begin{abstract}
Uma cidade ou urbe é uma área urbanizada, que se diferencia de vilas e outras entidades urbanas através de vários critérios, os quais incluem população, densidade populacional ou estatuto legal, embora sua clara definição não seja precisa, sendo alvo de discussões diversas. A população de uma cidade varia entre as poucas centenas de habitantes até a dezena de milhão de habitantes ${ }^{1}$.

Aglomeração humana localizada numa área geográfica circunscrita e que tem numerosas casas, próximas entre si, destinadas à moradia e/ou a atividades culturais, mercantis, industriais, financeiras e a outras não relacionadas com a exploração direta do solo; urbe ${ }^{2}$.
\end{abstract}

Para além da definição de "cidade" dessa enciclopédia colaborativa e virtual ou de qualquer outro dicionário, cada cidade tem suas especificidades, problemas, códigos, silêncios, vivências, culturas, imagens, tensões, contradições e carências. Cada cidade apresenta também uma história narrada em sua arquitetura, nos monumentos, vestígios, paisagens. Mas até que ponto estamos abertos para percebê-la? Como jovens alunos do Ensino Médio se apropriam do espaço citadino conseguindo reconhecer a história ali narrada? Para respondermos a tais questões, nos orientamos no sentido de incluir no ensino e na aprendizagem histórica do Ensino Médio a motivação para percorrer a cidade, considerando que, desta forma, os alunos teriam acesso a elementos que contribuiriam para uma maior capacidade de construção do conhecimento histórico. Contudo, já de início frisamos que o objetivo deste texto é considerar apenas as ideias dos alunos, sendo que não se pretende propor uma atividade didáticopedagógica mediante o uso do aplicativo Pokémon Go. É a própria atividade que nos proporcionou as narrativas para que fossem postas sob escrutínio na articulação entre ação e reflexão.

Tomamos como "dispositivo de evocação" um jogo de realidade virtual, o Pokémon GO. A escolha pelo jogo se deu para que pudéssemos nos aproximar do universo cultural dos alunos, entendendo que, enquanto o exercício de olhar para a história na e da cidade não é usual para estes sujeitos, o mundo virtual permite seu maior envolvimento.

A pesquisa foi realizada com as turmas do segundo ano do Ensino Médio, durante o $4^{\circ}$ bimestre de 2016 (outubro a novembro), após a aprovação da direção da escola que analisou o plano de ação didática, tendo como referencial o currículo aprovado pela equipe pedagógica $e$ as disposições legais ${ }^{3}$. A proposta de participação na pesquisa anunciada aos alunos também foi prontamente aceita, mesmo por aqueles que dela desconfiavam, devido ao uso do smartphone 
em aulas de história ${ }^{4}$. Houve a necessária autorização assinada pelos pais, lembrando que os alunos eram menores de idade. E mais um item foi incluído: um "contrato" realizado com os alunos, pois estes deveriam fazer as visitas aos espaços da cidade - os PokéStops acompanhados de algum responsável.

A atividade foi proposta pelo professor-pesquisador Arnaldo Martin Szlachta Junior aos alunos no ambiente escolar e compreendeu a seguinte problemática: Quais lugares da cidade de Maringá aparecem no jogo e o que você pensa sobre eles?

Em um primeiro momento, neste artigo, falamos um pouco sobre a cidade e suas histórias, especificando a cidade de Maringá. Depois, consideramos o jogo Pokemon Go e, brevemente, o vínculo entre o mundo digital e a sala de aula, para logo após destacarmos os passos da atividade do projeto de ensino e pesquisa, então vinculados à noção de aula-oficina $e$ matriz disciplinar rüseniana. Finalmente, recorremos às narrativas provindas dos alunos envolvidos que foram transpostas para os discursos-síntese para otimizar os procedimentos de análise.

\section{Estudar as narrativas históricas da cidade}

A proposta de ver na cidade o seu discurso histórico parte do princípio de que esse espaço é pleno de símbolos, pistas e indícios, o que demanda a opção, o empenho em tratá-lo como passível de observação, empatia e reflexão. O que vemos, descobrimos e compartilhamos na cidade na maioria das vezes, embora familiar porque próximo, não é reconhecido ou compreendido. Em outras palavras, nos habituamos com a cidade sem que necessariamente prestemos atenção a o que ela diz e o que silencia; daí a proposta didático-pedagógica de empreender no Ensino Médio a observação da cidade como condição para a construção do conhecimento histórico.

A cidade vem sendo tematizada no debate educacional em nível mundial "[...] como um lócus múltiplo, plural e permanente, passível de reinterpretação e ressignificação nos mais diferentes territórios e experiências sociais" (Miranda; Blanch, 2013, p. 63), sendo assim, seria pertinente "[...] a interpelação dos sentidos e consciência histórica que pode ser ativada a partir da experiência com a pluralidade urbana efetiva" (Miranda; Blanch, 2013, p. 66). A narrativa histórica se incorpora ao patrimônio histórico-cultural, considerando a ampliação do conceito, como tudo aquilo que valoriza as paisagens ou lugares naturais (em Maringá temos o Parque Ingá como lugar-símbolo), bem como um conjunto de práticas e representações que engloba as esferas artística, documental, científica, antropológica, religiosa, histórica, espiritual e outras. De 
acordo com Zanirato: "[...] o patrimônio é compreendido como os elementos materiais e imateriais naturais ou culturais, herdados do passado ou oriundos do presente, no qual um determinado grupo de indivíduos reconhece sinais de sua identidade" (Zanirato, 2009, p. 137). Nessa perspectiva, não podemos segregar ou pensar em uma classificação rígida, visto que mesmo o patrimônio material é reflexo da complexidade de uma sociedade que apresenta suas manifestações, intenções, desejos e medos.

Ainda temos circulando na História Pública representações que associam o patrimônio histórico às demandas da construção do Estado-Nação, que requeria a "elaboração de uma identidade coletiva, que pudesse ser compartilhada simbolicamente por todos os cidadãos, na medida em que pudessem se reconhecer como oriundos de uma mesma nação" (Cassol; Caimi, 2012, p. 80). A valorização do que era entendido como patrimônio histórico relacionava-se com políticas culturais que viessem "[...] fornecer meios para que compartilhassem valores $e$ costumes, para que pudessem se comunicar entre si, para que tivessem um solo e uma origem supostamente comuns" (Funari; Pelerini, 2006, p. 15). No contexto brasileiro, a ideia de patrimônio histórico se enraíza a partir da chegada da família real portuguesa à Colônia em 1808, quando "[...] operou-se um conjunto de ações preservacionistas, cujos principais alvos foram os bens referentes à colonização portuguesa, ou outros de alguma maneira relacionados com essa herança" (Cassol; Caimi, 2012, p. 80). Apenas o patrimônio de "pedra e cal", ou seja, somente as construções que representassem o que seria modernidade, progresso, civilização eram consideradas válidas como patrimônio histórico. Desta forma, se preservava apenas o patrimônio edificado, sendo a maior parte dos bens tombados relacionados à memória de grupos dominantes (Cassol; Caimi, 2012, p. 82).

Embora permaneçam concepções tradicionais quanto ao patrimônio histórico, elas vão se alargando e em 1972, na Conferência Geral de Genebra, definiu-se uma nova categoria, o Patrimônio Cultural da Humanidade, que contempla os bens de valor artístico, científico ou histórico, sendo que a UNESCO (Organização das Nações Unidas para a Educação, a Ciência e a Cultura) apresentaria sua própria classificação quanto a esses bens que abarca: Meio ambiente, Elementos não tangíveis e Bens culturais (Cassol; Caimi, 2012). Patrimônio histórico passa a ser visto como um bem móvel, imóvel ou natural, reconhecido como tendo valor para um país, uma sociedade, um povoado ou uma região, não ligado apenas um grupo social (dominante) ${ }^{5}$.

O patrimônio histórico-cultural é um instrumento pedagógico, formal ou não-formal, uma evidência e manifestação da cultura, "em todos os seus múltiplos aspectos, sentidos e significados", que permite "[...] levar as crianças e adultos a um processo ativo de conhecimento, apropriação e valorização de sua herança cultural, capacitando-as para um melhor usufruto 
destes bens, e propiciando a geração e a produção de novos conhecimentos, num processo contínuo de criação cultural" (Horta, Grunberg; Monteiro, 1999, p. 6).

Neste sentido, a cidade e seus patrimônios histórico-culturais podem ser compreendidos, segundo Barthes, como um conjunto de discursos ou escritas, ou ainda, como uma linguagem que possibilita a semiótica urbana: "[...] a cidade fala aos seus habitantes, nós falamos a nossa cidade, a cidade onde nós nos encontramos simplesmente quando a habitamos, a percorremos, a olhamos" (Barthes, 1985, p. 184). Se a cidade pode ser vista como um "texto", para Barros (2012, p. 45), o seu leitor privilegiado seria o habitante, ou o visitante, que se desloca através dela. "[...] o complexo discurso urbano aloja dentro de si diversos discursos de todas as ordens. A cidade também fala aos seus habitantes e aos seus visitantes através dos nomes próprios que ela abriga: dos nomes de ruas, de edifícios, de monumentos" (Barros, 2012, p. 45). Soma-se a isso o fato de que o "texto" da cidade ensina, portanto, integra o rol das pedagogias culturais, assim como o game, como veremos mais adiante neste texto.

A noção de "pedagogias culturais" abarca a concepção de que o ensino e aprendizagem - no caso, de história - não ocorrem tão somente nos espaços formais e/ou de forma explícita, mas permeiam o social, nas suas múltiplas relações e interações (Andrade; Costa, 2015). Entender que aprendemos nas várias dimensões sociais decorre de uma discussão que já acontecia na década de 60 do século passado. Com o conceito de "currículo oculto" (Apple, 1982) ou "currículo ativo" (Goodson, 1991) que compreende a produção do currículo escolar para além do prescrito e regulamentado, também de "pedagogia invisível" (Bernstein, 1984), cujo pressuposto seria que os conteúdos ensináveis são transmitidos e apreendidos de maneira difusa, não-estruturada ou não-específica. $\mathrm{Na}$ atualidade, pedagogias culturais subentendem mensagens, noções, crenças, ideias veiculadas nos vários artefatos culturais como filmes, propaganda/publicidade, revistas de consumo, músicas, séries televisivas, novelas etc. Tais mensagens circulam no social e ajudam, interferem, refletem na (re)construção de sujeitos, de identidades e de alteridades, ou seja, na disseminação ou modelização de práticas e representações que podem (des)potencializar determinados modos de ser, pensar e viver na contemporaneidade. Enfim: a cidade é aqui compreendida como pedagógica, como um texto curricular, porque ensina, porque produz racionalidades, subjetividades, identidades e saberes (inclusive, históricos).

Em geral, a história narrada na cidade é "oficial", o que não é diferente com a cidade de Maringá ${ }^{6}$, entendendo aqui como História Oficial aquela que se consagra em diversos meios, geralmente edificando a atuação de determinado grupo social. Seria, segundo Maryine Crivello (2013), a história popularizada pela mídia, pelas comemorações, pelos discursos, em especial, os 
políticos; desatualizada do ponto de vista da (maioria da) historiografia; tende a ser lúdica e/ou espetacularizada, bem como engajada emocionalmente (orgulho de pertencer a uma sociedade de pretenso passado glorioso); ressalta heróis e ignora as relações de poder e os conflitos. A historiografia, muitas vezes, também abraça a História Oficial, mas é nas experiências travadas na História Pública que entramos mais em contato com ela.

Todos nós nos afeiçoamos ao lugar onde moramos, nos identificamos como um grupo pertencente a uma cidade. A nosso ver, este "orgulho" é válido, desde que pautado em uma visão crítica, contextualizada historicamente, que por isso mesmo adentra tanto na imagem positiva como negativa da cidade, com seus avanços, problemas, conflitos e silêncios. Enfim, subverter a História Oficial não significa necessariamente distanciar-se da relação afetiva que temos com nossa cidade. Podemos dizer o mesmo sobre o patrimônio histórico de uma cidade, pois este continua sendo um elo que nos une em torno de uma identidade, mas agora podemos atualizar o conceito, entendendo que essa unidade se constrói através da pluralidade formada pela diversidade de grupos que compõem uma sociedade e suas expressões econômicas, culturais, históricas e políticas.

\section{O uso de um aplicativo game como recurso didático}

O objetivo da pesquisa foi o de percorrer a cidade para ver qual história ela conta, tendo como mediação um jogo de realidade virtual. Além deste procedimento, recolhemos as narrativas dos alunos sobre o que viam na cidade, ou seja, tais narrativas foram compreendidas como manifestação das representações que tinham sobre a cidade.

Usamos o conceito de representação na direção de Nicole Tutiaux-Guillon: "A representação social é um produto cognitivo que mistura experiência, julgamento, conhecimento, afeto e resulta de uma interação social e socialização" (Tutiaux-Guillon, 2011, p. 23). São noções, saberes, ideias, insights, construídos de forma não científica (embora também fragmentos da ciência sejam incorporados) e que permeiam a comunicação, a compreensão. Mais ainda: interferem na decisão e ação (Tutiaux-Guillon, 2011, p. 24). As perguntas destinadas aos alunos nesta pesquisa configuram uma estratégia de direcionar uma forma de conhecimento situacional, ou seja, ao aluno "[...] pede-se que pense em determinado recorte da realidade que se apresenta e que procure uma posição ou ponto de vista em relação a ela" (Edwards, 1997, p. 24). Este tipo de pergunta prioriza as vivências dos alunos, a significação de uma realidade, os usos e sistemas valorativos que possui. Neste sentido, a pergunta-problema envolvia descrever e analisar os pontos da cidade de Maringá que aparecem como PokéStops no 
jogo Pokémon GO.

Além disso, é importante trazer a categoria de pedagogias culturais para a própria definição multidisciplinar (e não limitante) de game, pois este também ensina. Marcella Albaine Farias Costa ressalta, utilizando-se de vários referenciais, que o jogo permite ampliar os conhecimentos gerais, desenvolver a atenção e o reflexo, bem como a socialização e a capacidade de lidar com perdas e vitórias. Os videogames podem servir como ferramentas para "[...] aumentar a capacidade do cérebro para o aprendizado, ajudando no controle cognitivo, na habilidade espacial, no autodomínio, na autoconfiança. No desejo de aprender, na motivação e na excitação (Costa, 2017, p 26-27).

Luís Carlos Petry, quando propõe tratar do conceito ontológico de jogo, elenca algumas características que configuram sua natureza: é uma atividade com regras, conflitos, objetivos, tem pontos de tomadas de decisão, ou seja, ao mesmo tempo que integram a cultura, também a ressignificam e a reproduzem (Petry, 2016). Petry também destaca que os jogos não são algo recente, mas se atualizaram conforme o contexto de uma cultura, hoje midiática/digital, assim como são ao mesmo tempo entretenimento, brinquedo, narrativas históricas, objeto educativo, psicoterapia, propaganda/marketing, promotores do sentimento de comunidade, potencializadores de mudanças no comportamento e na opinião na vida pública, bem como no consumo (Petry, 2016). Para Huizinga (1999) o jogo realiza-se sempre em um espaço e tempo, através de regras consentidas, mas obrigatórias, e orientam-se sob sentimentos de tensão, alegria e de uma consciência suspensa da realidade. Já Marcelo Fardo entende que o jogo abarca “[...] narrativa, sistema de feedback, sistema de recompensa, conflito, cooperação, competição, objetivos e regras claras, níveis, tentativa e erro, diversão, interação e interatividade" (Fardo, 2013, p. 1). No caso do jogo Pokémon Go, todos estes elementos estão presentes: o jogador é chamado a fazer escolhas em um ambiente regulado e permeado pela competição e conflitos; existe uma narrativa histórica na medida em que se cumpre etapas e se recolhe recompensas conforme um objetivo final; há uma comunidade de interesses, não é possível apenas jogar sozinho, mas a tomada de decisão é individual; há uma instrução articulada com a ideia de patrimônio histórico, embora não seja este o objetivo deliberado deste game.

Pokémon é uma franquia de desenhos japoneses que fez grande sucesso na década de 1990, sendo que a nomenclatura está associada a poket monsters, cuja tradução livre significa "monstros de bolso". O game Pokémon GO foi produzido em 2016 conforme parceria de empresas como Nintendo, Niatic e The Pokémon Company e faz um resgate da temática do desenho da TV, transformado em um jogo eletrônico de caçador e jogador free-to-play (que pode ser baixado gratuitamente) voltado para smartphones, para as plataformas iOS e Android. 
Em fevereiro de 2018 o jogo foi atualizado, inclusive com novos PokéStops, e no momento em que escrevemos este artigo ocorre uma maratona do jogo na cidade. A proposta do game se sustenta em ações de acordo com a "realidade aumentada", ou seja, a integração ou justaposição de informações virtuais e de visualizações do mundo real, criando um ambiente misto em tempo real.

Neste game específico, faz-se o uso do localizador GPS $^{7}$ e da câmera de dispositivos compatíveis, permitindo aos jogadores capturar, batalhar e treinar criaturas virtuais, chamadas Pokémon, que aparecem nas telas de dispositivos como se fossem no mundo real através da geolocalização. Cada Pokémon tem algum tipo de poder, e consequentemente, de pontos. Nos PokéStops se mistura o real (o endereço físico) com o virtual (espaço do game) e é onde o usuário consegue pontuação para subir de nível no jogo e consegue também as pokebolas, que são os recipientes para armazenar os "monstros" virtuais. Já os Ginasiums, são os locais que seguem a mesma mescla do real com o virtual, na qual acontecem as competições entre os jogadores e seus "monstros" virtuais, os Pokémons. Não é necessário ficar no local dos Ginasiums, ou seja, o jogador passa por este e se inclui nas disputas recebendo o resultado horas depois. Esse resultado depende de como está seu "monstro" Pokémon, de acordo com critérios que podem ser observados na captura ou em ações, sendo que tais resultados se encontram armazenados em uma espécie de incubadora, em estado de progressão conforme as disputas travadas.

Além de procurar esses "monstros" virtuais, na plataforma do game em alguns pontos do GPS aparecem, como já dissemos, também os PokéStops e Ginasiums. Estes são pontos inseridos nos mapas, geralmente espaços públicos de grande circulação de pessoas. A produtora Niantic, explicou que os dados que Pokémon Go utiliza para determinar Gyms e PokéStops são fruto de três anos de trabalho, que começou com base inicial do Google. O buscador oferecia várias informações sobre milhares de locais históricos, artes públicas, estátuas e comércios. Essa base foi utilizada em um outro game da Niantic, chamado Ingress, o qual também utilizava localidades do mundo real em sua jogabilidade. A lista de locais foi adaptada para o Pokémon Go e usuários eram capazes de enviar suas próprias sugestões para serem adicionadas. Havia regras para enviar uma sugestão, sendo que o local deveria ser seguro, acessível publicamente e ser um trabalho de arte, peça de arquitetura, ponto turístico, patrimônio histórico ou um comércio local importante. Os locais eram conferidos por uma equipe que avaliava se eles atendiam estes critérios.

Pokémon Go foi lançado com muitas críticas: os frequentes problemas técnicos que se evidenciaram no lançamento, os muitos acidentes decorrentes do seu uso, em especial, os furtos 
de celulares e muitos ressaltaram que o jogo perturbava a ordem, fazendo pessoas não respeitarem os espaços públicos e privados, invadindo locais perigosos e particulares para conseguirem os pokémons mais $\operatorname{raros}^{8}$. De outro lado, empresas queriam que seus espaços fossem incluídos no jogo como PokéStops ou Ginasiums para melhorarem a circulação de pessoas e assim, aumentar o faturamento. Muitos entenderam que o jogo acabava estimulando a atividade física dos jogadores, na medida em que, geralmente, o público do jogo virtual tende a ser mais sedentário. Polêmicas à parte, o jogo acabou se tornando um fenômeno global e um dos aplicativos móveis mais utilizados em 2016, tendo sido baixado mais de 750 milhões de vezes em todo o mundo.

A humanidade vem passando por duas grandes transformações que afetam consideravelmente a sociedade: a primeira está relacionada com o advento da sociedade do conhecimento e a globalização, sendo que no início do século XXI assistimos à preponderância do uso da informática na informação e na comunicação entre as pessoas, e após 2007 isso se intensifica com a popularização dos equipamentos móveis (como tablets e smartphones) e pela acessibilidade da internet móvel por chips de operadoras de celular (Moran, 2010).

As novas tecnologias perpassam e impactam toda a vida cotidiana das pessoas, inclusive a sala de aula. De acordo com Straubhaar e LaRose (2004), a presença dos recursos digitais vem transformando racionalidades e sensibilidades. Embora não haja como afirmar que a (nova) Tecnologia de Informação e Comunicação (TIC) seja a realidade de toda sociedade ou de toda escola, devido à inclusão digital ainda não suficiente no Brasil, ela exerce fascínio, cooptando principalmente os sujeitos que integram o grupo infanto-juvenil. Eles são considerados "nativos digitais", enquanto seus professores seriam "imigrantes digitais". Os nativos digitais são aqueles que "[...] nasceram num mundo imerso em tecnologia digital e desde sua infância convivem com aparatos diversos e associam um botão de mouse como porta para um grande mundo virtual". Entretanto, os professores "[...] observam o mouse como recurso a ser transposto, com habilidades a serem construídas", com certa dificuldade de "[...] assumirem a necessidade de se criar modelos pedagógicos inovadores que incorporem essas possibilidades ofertadas pelo ciberespaço" (Campos; Giraffa, 2011, p. 9).

Os atos de "[...] ensinar e aprender são desafios que enfrentamos em todas as épocas $e$ particularmente agora em que estamos pressionados pela transição do modelo de gestão industrial para o da informação e do conhecimento" (MORAN, 2010, p. 12). Há que se destacar que a dificuldade dos professores não é apenas lidar com a informática, que requer o domínio de técnicas ou habilidades com o computador e afins, mas sim de explorar a cibercultura ou ciberespaço. Dificuldade esta, que não pode ser vista como mera "resistência" às TICs, mas 
como resposta à infraestrutura ineficaz e à falta de capacitação tecnológica que deveria ser efetivada pelos órgãos públicos reguladores da educação.

Consideramos o lado positivo do uso das TICs, mas não por isso nos distanciamos do fato de que estas não salvarão a escola e a educação. No caso da disciplina escolar de história, a apresentação de filmes, músicas, slides, websites, pode ser usada como mera ilustração ou reforço dos conteúdos não problematizados, o que rompe com a ideia de novidade e/ou modernidade. Ou seja: o uso das TICs não promove por si só a renovação do ensino se os conteúdos são tradicionais. "Os recursos semióticos que encontramos nas telas dos computadores (e nos celulares) são basicamente os mesmos que podemos encontrar em uma sala de aula convencional: letras e textos escritos, imagens estáticas ou em movimento, linguagem oral, sons, dados numéricos, gráficos, etc." (Cool; Mauri; Onrubia, 2010, p. 76). Quando podemos juntar conteúdos renovados com as TICs digitais, podemos, sim, ter a possibilidade de

[...] criar ambientes que integram os sistemas semióticos conhecidos e ampliam até limites inimagináveis à capacidade humana de (re)presentar, processar, transmitir e compartilhar grandes quantidades de informação com cada vez menos limitações de espaço e de tempo, de forma quase instantânea e com um custo econômico cada vez menor (Cool; Mauri; Onrubia, 2010, p. 76).

Como dissemos, as TICs alteraram de forma significante o nosso cotidiano (mesmo considerando a exclusão digital e o despreparo dos imigrantes digitais) e nos últimos anos houve a ascensão de dispositivos de comunicação móveis dotados de habilidades como internet móvel de maior velocidade e multimídia. $\mathrm{O}$ uso dos celulares ou tablets passou a fazer parte das possibilidades de aprendizagem móvel, a mobile learning.

\section{A práxis da pesquisa no ambiente escolar}

A pesquisa-ação educacional é uma estratégia de articulação entre pesquisa e ensino, geralmente desenvolvida por professores-pesquisadores. As pesquisas realizadas tendo como base a própria atuação em sala de aula servem para aprimorar o ensino e aprendizagem histórica. Para David Tripp, este procedimento exige um "ciclo de investigação-ação". Segundo ele, "A solução de problemas, por exemplo, começa com a identificação do problema, o planejamento de uma solução, sua implementação, seu monitoramento e a avaliação de sua eficácia" (Tripp, 2005, p. 446). Neste caso, a referida "solução de problemas" requer que voltemos às narrativas dos alunos para visualizar quais seriam eles. A pesquisa-ação no campo da história, encontra referências no texto de Isabel Barca de 2004 cujo fundamento é a "aula- 
oficina”. Nela, diferentemente das aulas de história expositivas, propõe-se aulas construtivistas reguladas pelo princípio investigativo. Da mesma forma que na pesquisa-ação descrita por Tripp, na aula-oficina a pesquisa começa pelo professor, que por sua vez, faz com que os alunos também construam o conhecimento histórico por intermédio da pesquisa.

A aula-oficina, fundamentada por Isabel Barca (2004), embora não tenha a matriz rüseniana como referencial explícito, nos faz reportar a ela. A matriz disciplinar da história, para Jörn Rüsen, quer dizer que História e a vida prática são relacionadas conforme a constituição de cinco fatores ou princípios: "carências de orientação, perspectivas orientadoras da experiência do passado, métodos de pesquisa empírica, formas de apresentação e funções de orientação". Rüsen entende que esta matriz é um "sistema dinâmico", em que um princípio leva ao outro, "até que no quinto, volta-se ao primeiro" (Rüsen, 2001, p. 35). Dito de outra maneira: parte-se da vida prática, dos problemas do cotidiano, e "volta-se" a esta vida prática, porém com um conhecimento mais elaborado, crítico e transformador.

O ponto de partida são os interesses configurados na vida prática para que haja a produção do conhecimento histórico, seja este especializado ou não. Em outras palavras, o estudo do passado parte das carências de orientações, das problemáticas que se apresentam no presente e/ou no cotidiano, e estas necessidades orientam a vida na estrutura do tempo (Rüsen, 2010, p. 25). Na pesquisa, entendemos estes "interesses" como sendo a problematização lançada: a história que a cidade nos conta.

Após lançada a pergunta-problema, focando a cidade como espaço em que todos habitam, compartilham, experienciam o cotidiano, buscou-se, junto aos alunos, conhecer o aplicativo. Na ocasião, esse game estava sendo bastante comentado nos meios de comunicação como um fenômeno mundial e como uma mudança radical nos hábitos das pessoas. Os alunos salientaram como o jogo era apresentado nas reportagens e na medida em que estávamos tratando de uma pesquisa e experimento com o celular na sala de aula, muitos procuraram em seus smartphones - googlearam como eles mesmo dizem -, assuntos como a perturbação da ordem e a invasão de espaços privados dos jogadores que buscavam os Pokémons. Tal iniciativa foi primordial para demonstrar a importância de estabelecer os limites saudáveis entre o mundo real e a proposta virtual do jogo.

Um dos encaminhamentos que tivemos posteriormente em sala de aula foi debatermos o patrimônio histórico, pois os PokéStops e Ginasiums costumam se localizar, como já mencionamos, nos locais de maior passagem das pessoas: praças, monumentos, escolas, igrejas, parques, universidades, monumentos etc. Esta etapa denomina-se Ideias, conforme a matriz disciplinar de Rüsen. É muito comum que tais locais sejam patrimônios histórico-culturais da 
cidade, mesmo que ainda não reconhecidos como tal (vide imagem 1 que retrata o grafite " $\mathrm{A}$ máquina do mundo" presente na Universidade Estadual de Maringá), como PokéStops. Nesta etapa, não apenas o jogo foi discutido, exigindo uma pesquisa-prévia, mas também o patrimônio histórico-cultural, buscando-se autores que tratavam da questão. Este levantamento de estudos sobre patrimônio constituiu nossa fundamentação teórica. "Elas [essas localidades] constituem, assim, as perspectivas gerais nas quais o passado aparece como história. Elas formam modelos de interpretação para os quais as experiências da evolução temporal do homem e de seu mundo são transpostas e nos quais são integradas" (Rüsen, 2001, p. 32).

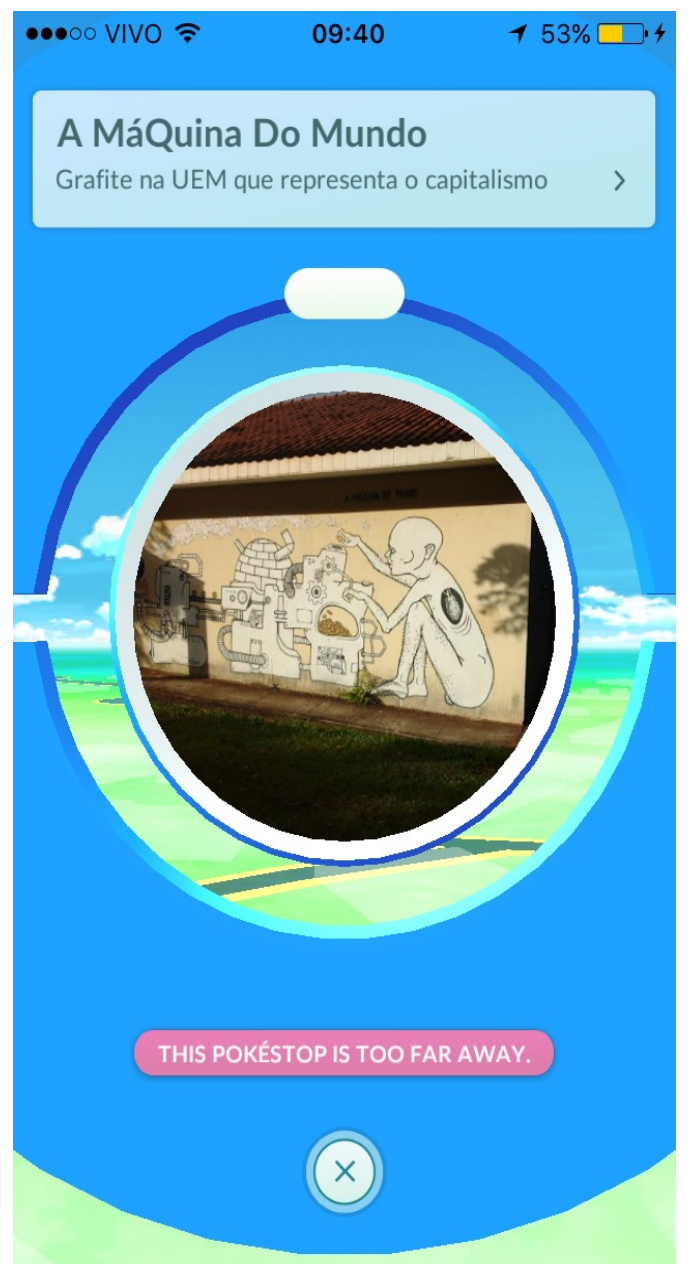

Figura 1 - Captura de tela de smartphone do game mostrando um dos PokéStops na cidade de Maringá no Paraná

Nossa ideia era demonstrar aos alunos que os patrimônios culturais não são algo distante, institucionalmente constituído e necessariamente "velho". Esse debate, além de necessário, se faz mais pertinente, visto que a cidade na qual aconteceu a pesquisa é relativamente nova (68 anos em 2019), o que pode levar ao entendimento de que seus artefatos, 
espaços e práticas não pertenceriam a uma construção patrimonial, segundo uma concepção já ultrapassada pela historiografia. Como destacou Pierre Nora, "[...] os meios de memórias foram destruídos pelo fenômeno da mundialização, globalização, colonização, industrialização, que ocasionaram o fim das sociedades-memória, mantenedoras e transmissoras dos valores" (Nora, 1993, p. 15). Isto que gera a ideia de que o que é "novo" não se coaduna com o que é considerado memória, tradição, patrimônio.

Um dos elementos que chamou atenção no debate na sala de aula com os alunos foi a preocupação destes em preservar o que é considerado antigo, mas foi perceptível o fato de que se referiam apenas aos artefatos materiais. Discutimos sobre práticas e usos, considerando que espaços muitas vezes utilizados como local de expressão artística têm sua importância patrimonial, mesmo não sendo tão antigos.

Procuramos estender o conceito de patrimônio histórico-cultural, entendendo que a imagem de uma cidade não se reconhece apenas na sua conformação físico-natural, mas por suas "expressões" (outdoors, cartazes de cinema, grafites); pelos seus próprios habitantes (o hippie que vende seus artesanatos, o vendedor de ervas ou de passes para o transporte público, a indígena que oferece balaios, o catador de papel que trabalha acompanhado de seu cachorro vestido com a camisa da CBF etc.).

Uma cidade então, do ponto de vista da construção imaginária do que representa, deve responder, ao menos, por condições físicas e naturais construídas; por alguns usos sociais; por algumas modalidades de expressão; por um tipo especial de cidadãos em relação com os de outros contextos, nacionais, continentais ou internacionais; uma cidade faz uma mentalidade urbana que lhe é própria (Silva, 2011, p. XXV).

Na sequência deste tipo de discussão, verificamos quais aparelhos eletrônicos os alunos dispunham e se eram compatíveis com o game, pensando junto com eles em uma melhor forma de executar nosso experimento pedagógico sobre o ensino de história. Assim, decidimos mapear previamente os PokéStops e também foram orientados no sentido de que a atividade poderia ser realizada em grupo para "economizar" na quantidade de celulares.

Os lugares elencados pelos alunos foram os mais próximos de suas casas e próximos à escola, dos quais destacamos os seguintes: Praça dos Expedicionários, Cine Teatro Plaza, Totem da História de Maringá, Praça Rocha Pombo, Praça General Gomes Carneiro, Maringá Honganji (Templo Budista), Largo Pioneiro Irineu Murazzi, Praça Farroupilha, Universidade Estadual de Maringá, "O menino do bueiro" (grafite localizado na Universidade Estadual de Maringá), Homenagem a Cristóvão Colombo e "A leitora" (escultura em madeira localizada na Universidade Estadual de Maringá) $)^{9}$. 
As orientações dadas foram para que os alunos visitassem os espaços indicados no aplicativo, entendendo que eles são fontes históricas que deveriam ser interpretadas. Assim, a cidade foi entendida como repleta de fontes que contavam a história, por isto essa etapa foi denominada "Métodos". Para Peter Lee, para construir o conhecimento histórico em sala de aula nos aproximamos do método da historiografia, segundo um "compromisso de indagação" com as "marcas de identificação" da história, como passado, acontecimento, evento, causa, mudança etc. - "o que requer um conceito de evidência" (Lee, 2006, p. 136). Assim, o uso escolar do documento histórico também é uma metodologia didático-pedagógica importante, porque atada à investigação histórica. A utilização da fonte documental remete ao fundamento do método histórico, aos processos necessários à construção do conhecimento histórico, seja pelos historiadores, seja pelos professores e alunos em sala de aula, na medida em que é preciso construir, juntamente com o estudante, os meios para que ele "[...] entenda os procedimentos da construção historiográfica e como o historiador analisa os vestígios nos documentos para escrever história" (Cainelli; Tuma, 2009, p. 212).

A atividade foi finalizada com a solicitação de que os alunos escrevessem um texto sobre o local que iriam visitar, sendo que poderiam expor o significado do local articulado com suas experiências, bem como associá-lo aos estudos realizados na disciplina de história daquela série ou em qualquer momento da vida escolar. Isto para dar condições de demonstrarem mudanças conceituais, explicações, interpretações, relações, argumentações, sistematizações $e$ contextualizações. Esse texto ou relatório comporia o resultado da pesquisa, seria uma "Forma de apresentação do discurso histórico" (a quarta etapa da matriz disciplinar de Rüsen). Não apenas a historiografia, mas toda forma de apresentação da narrativa histórica "[...] torna-se uma prática cultural de interpretação do tempo. A plenitude do passado, tornado presente, devese a uma atividade intelectual a que chamamos de 'história' e que pode ser caracterizada como uma narrativa" (Rüsen, 2001, p. 149). Para Jörn Rüsen, quando empreendemos uma narrativa histórica, dotamos de significado/sentido histórico às nossas experiências e por isso a narrativa histórica seria uma "operação mental constitutiva" (Rüsen, 2010, p. 43). Isabel Barca resume: seria expressar sua interpretação e compreensão, ou seja, a história aprendida, "[...] utilizando a diversidade dos meios de comunicação atualmente disponíveis" (Barca, 2004, p. 134).

$\mathrm{Na}$ semana seguinte, a maior parte dos alunos trouxe suas narrativas, o que não esperávamos, pois não houve protelação, comparado aos trabalhos anteriormente solicitados. Ao observar as narrativas, percebemos que havia uma ligação muito pessoal e até afetiva em relação aos espaços, o que provavelmente facilitou a construção do conhecimento histórico. 


\section{Narrativas dos alunos sobre alguns lugares da cidade (PokéStops)}

Torna-se pertinente, neste momento do artigo, categorizar as narrativas dos alunos sobre os PokéStops, isto é, sobre os lugares de história com os quais tiveram contato ao percorrer a cidade através do jogo. Para isso usamos a concepção de "discurso-síntese". No discurso-síntese se reúnem conteúdos e argumentos que conformam opiniões semelhantes. Assim, apanhamos as respostas semelhantes como se fossem um depoimento único (Lefebre; Lefebre, 2012, p. 17-19). Esta metodologia se aproxima daquela denominada Discurso do Sujeito Coletivo (DSC) e serve ao propósito de reunir depoimentos verbais e não verbais em discursos-sínteses, entendendo que em qualquer sociedade os sujeitos compartilham, também divergem em ideias, noções, opiniões e representações e, por isso mesmo, estas podem ser percebidas conforme padrões, fazendo o pensamento coletivo "falar diretamente" (Lefebre; Lefebre, 2012, p. 24). O discurso-síntese seria a mensagem nuclear de um conjunto de narrativas e não deixa de ser uma forma de categorização, de reconhecer, diferenciar e classificar aproximadamente as representações sociais.

Sobre as narrativas dos alunos quanto aos lugares que visitaram, através do jogo, as classificamos da seguinte forma:

1) Percepção sobre o lugar: A primeira mensagem nuclear visível nas narrativas dos alunos é o fato de que alguns deles já haviam passado por determinado lugar (PokéStop), mas nunca tinham se atentado para o mesmo, para seus detalhes, para sua relação com a noção de patrimônio histórico-cultural ou com algo que se configurava importante para se caracterizar a cultura de Maringá: "Eu passo nessa praça [Praça dos Expedicionários] todos os dias para ir no serviço da minha mãe, não sabia o nome dela" (Aluna 1) ${ }^{10}$; "Nunca tinha percebido que havia uma placa nessa praça [Homenagem a Cristóvão Colombo], li e não há muita informação sobre Colombo" (Aluno 2) e "A praça Farroupilha fica perto da minha casa, não sabia que era o nome do espaço, pessoal lá do Alvorada chama de praça da avenida" (Aluna 7).

2) Experiência no lugar: Dois alunos demonstraram que usavam o lugar e contam suas experiências: a Aluna 7, por exemplo, mesmo não sabendo o nome correto da Praça Farroupilha, nos conta que: "Quando eu era mais nova eu ia com as crianças brincar lá, antes tinham uns brinquedos que ficaram velhos e depois a prefeitura tirou. [...] Antes tinham uns senhores lá que ficavam jogando xadrez, mas eles deixaram de ir lá, talvez eles morreram". A narrativa da aluna remete ao passado, pois, da forma que descreve, a praça parece agora vazia, talvez abandonada. A cidade apresenta mudanças e permanências, está sempre em um movimento de (re)construção e desconstrução e, assim, também os sujeitos mudam a forma de 
vê-la e de usá-la. O aluno 8 nos narra sua experiência, no caso com o grafite "A máquina do mundo", presente na UEM (Figura 1): "Passo todos os dias por essas pinturas e muitas vezes já me disseram que ela seria apagada e isso me deixa muito triste". Também a aluna 9 associa o Cine Teatro Plaza com suas vivências: "Eu sempre vi esse lugar fechado, nunca entrei lá, durante o dia é um lugar cheio de pessoas, tem um cachorrão ali na frente que é de uma parente de uma prima lá".

3) Descoberta sobre o lugar e o nome do lugar: Dois alunos mostraram desconhecer o porque de praças terem determinado nome: "Eu não sabia o que era um expedicionário [Praça dos Expedicionários] e como tive que fazer o trabalho perguntei pro pessoal de casa e ninguém sabia" (Aluna 1) e "Eu não sei quem foi Gomes Carneiro [Praça Gomes Carneiro], não achei em nenhum lugar" (Aluna 3). A aluna 1 procurou saber com o seu professor de filosofia o que eram os expedicionários e acabou gostando da explicação sobre "os soldados que foram pra guerra".

4) Saberes escolares sobre o lugar: Dois alunos sabiam o porquê do nome das praças devido às informações obtidas nas aulas de História: "Sobre ele [Homenagem a Cristóvão Colombo] eu sei que estudamos esse ano e foi a primeira pessoa a chegar na América com uma ideia de ir para as Índias porque lá tinha muitas especiarias que faziam os países da época ganhar muito dinheiro" (Aluno 2); "Este ano aprendi com o professor Arnaldo que a Farroupilha [Praça da Farroupilha] foi uma guerra no Rio Grande do Sul enquanto o Dom Pedro ainda era criança" (Aluna 7). A aluna 8 também tece sua interpretação sobre "A máquina do tempo" (grafite na UEM) associando-o com o conhecimento construído em sala de aula: "Lembro das aulas da professora Débora quando ela falou do feudalismo ano passado [...]".

5) Questionamento quanto à História Oficial: Os alunos não somente descreveram os lugares, mas demonstraram ter uma visão crítica. O Aluno 2 até pondera que a cidade parece gostar muito de Colombo, pois tem a homenagem e tem uma rua com o nome dele, mas questiona: "Mas de verdade eu acho que a cidade deveria valorizar mais as pessoas de Maringá ou do Paraná, tem muito nome de praça e rua de gente de fora". De fato, a "Homenagem a Cristóvão Colombo" em uma praça pode ser considerada um "lugar de memória", um monumento que remete à história oficial, consagrada. Porém, o aluno termina por propor a continuidade desta lógica dos nomes consagrados, apenas mudando os nomes para personagens da História Local. Neste ponto, precisamos fazer um adendo: existem PokéStops que nos mostram lugares com nomes locais, nomes dos chamados "pioneiros", geralmente políticos, mas não existem muitos que homenageiam os indígenas, por exemplo. A cidade parece adotar a ideia de "vazio demográfico", como na História Pública ou na historiografia tradicional, visto que os PokéStops só integram o jogo por serem lugares de grande fluxo das 
pessoas, portanto, ou estes lugares não existem, ou são muito afastados, não muito frequentados, ou ainda, desconhecidos. A ausência do indígena na história da cidade, deste modo, não é um problema do jogo, mas da permanência de uma história que silencia, marginaliza e exclui grupos minoritários, em especial o indígena.

A "Praça do Peladão", onde há uma escultura de Henrique Aragão, designado com o mesmo nome na cultura popular, na verdade é o "Monumento ao Desbravador", aquele que supostamente chegou primeiro, derrubando a mata. No Parque Ingá, há também a "Estátua em Homenagem ao Pioneiro" com a mesma inspiração, ou seja, edificar aqueles que, segundo a História Oficial circulante na cidade, formaram/construíram a cidade. Vários bustos de políticos compõem a paisagem de Maringá (todos PokéStops): Ary de Lima (vereador maringaense em 1967); Heitor Alencar Furtado (político paranaense que iniciou sua carreira em Maringá); Adriano Valente (prefeito da cidade de 1969 a 1972). Também há um busto de Melvin Jones, fundador do Lions Clube Internacional e uma efígie de Gastão Vidal, político brasileiro. Também há uma rua com nome de um agrimensor: Nelson de Souza Figueiredo. Homenagens como placas, nomes de praças e ruas, estátuas, bustos e efígies nos indicam quem é considerado digno de homenagem, o personagem importante, o "herói". Há apenas um "herói" que não se enquadra na identidade do homem branco e cristão; é a "Cabeça de Zumbi dos Palmares", na Praça Zumbi dos Palmares. Contudo, existem homenagens aos abolicionistas: Ruas Joaquim Nabuco, Luiz Gama, José do Patrocínio etc.

A aluna 3, já havia mencionado a Praça General Gomes Carneiro, um militar brasileiro com participação na Guerra do Paraguai e na Revolução Federalista. Para Reginaldo Benedito Dias (2000), esses nomes com os quais se batizam ruas, avenidas, monumentos etc. têm uma historicidade, ou seja, mudam conforme o contexto histórico, mas em geral permanecem como nomes ligados à História Oficial ${ }^{11}$. Este historiador lembra que as ruas paralelas à Avenida Brasil fazem, quase sempre, referência à Guerra do Paraguai.

6) Questionar a preservação: Os alunos também questionaram o descaso dos órgãos públicos com determinados lugares: "Eu acho que a sociedade não liga para a cultura, já quiseram transformar lá [Cine Teatro Plaza] num estacionamento ou mercado. Tá no centro da cidade e está praticamente esquecido pela prefeitura. Já no meu bairro não tem teatro e quando queremos fazer alguma coisa usamos a cancha, eu acho que deveríamos valorizar mais nossa cultura" (Aluna 9). A aluna 3 fala do abandono da Praça General Gomes Carneiro por parte das pessoas que habitam a cidade: "[...] lá tem uns bancos, que tá tudo cagado de passarinho e um pé de pitanga que tinha muito no chão, quase tudo perdido. Ninguém vai lá pegar as grutinhas, acho que como tá todo mundo ocupado, passa e nem vê " (Aluna 3). 
7) Noção de patrimônio histórico: Três alunos associaram os lugares ao conceito de patrimônio histórico. Sobre o grafite "Menino do bueiro" (UEM), a Aluna 4 alertou para o entendimento de que um grafite é patrimônio histórico porque é arte e preocupa-se com a hipótese de acabarem com ele. "Uma das coisas que pensei é como uma pintura poderia ser chamada de patrimônio histórico, para as pessoas lembrarem o que foi é necessário tirar fotos e guardar. A pintura descasca com o tempo e ainda tem aqueles que não enxergam que ali tem arte e pintam por cima". Já o Aluno 5 entende que o patrimônio histórico é também um dispositivo pedagógico, o que se coaduna com nossa perspectiva sobre as pedagogias culturais da cidade: “[...] um patrimônio histórico é algo que ficará, vai permanecer lá e vai 'ensinar' as pessoas". A aluna 9 mostra que mudou de concepção quanto ao patrimônio histórico: "Eu achava que patrimônio histórico era só coisa antiga e mais bonita e apresentável, aquele teatro [Cine Teatro Plaza] é novo e não tem uma arquitetura".

8) Estranhamento em relação ao lugar: Esta aluna 9 também demonstrou certo estranhamento em relação ao teatro, visto que é fácil perceber que ela não gostou do lugar, achando-o feio e abandonado e indo mais além: "[...] à noite lá é um lugar perigoso, cheio de travecão e drogados, dá muito medo lá à noite". O mesmo aconteceu com o aluno 6, pois ele não gostou do Templo Budista Maringá Honganji, mas seus motivos foram outros, baseado em seu desconhecimento e certo preconceito em relação a outra religião: "Eu acho que é uma religião de japoneses, eles seguem outros deuses que não é o nosso senhor Jesus Cristo". No entanto, este aluno encontrou o Templo fechado e ficou curioso com o local: "Eu fiquei curioso para saber o que fazem ali, como seria o cultuo deles, mas eles colocaram grades e aí fica difícil entrar lá".

9) Reflexões elaboradas: As narrativas dos alunos nos fazem ver que são capazes de produzir uma interpretação mais satisfatória (histórica) sobre o lugar. $\mathrm{O}$ aluno 4 menciona a questão do grafite como arte: "Eu conheço o pessoal do grafite, e como tem muita gente que critica o trabalho deles dizendo que fazem pixe e na verdade fazem arte". E procura entender o grafite "O menino no bueiro": "Essa pintura da UEM mostra um menino no bueiro, que eu entendo que ele vive uma situação de perseguição, precisa fazer as coisas escondidas". O aluno 5 entende sobre a escultura denominada "A leitora": "Ela é feita de madeira e mostra uma mulher com um livro na mão, é uma valorização do estudo já que o estudo é que faz as pessoas evoluírem na vida".

A aluna 8 respondeu de forma crítica sobre "A máquina do mundo" (UEM), demonstrando um raciocínio histórico 
Passo todos os dias por essa pintura e muitas vezes já me disseram que ela seria apagada e isso me deixa muito triste. Eu acho que essa pintura incomoda as pessoas que possuem mais dinheiro que as outras, eu acho que é porque há uma crítica sobre a exploração que o capitalismo faz sobre as pessoas e por mais que a gente lute para mudar a coisa é tão amarrada que não conseguimos sair. [...] e na real eu acho que no fundo vivemos numa sociedade como aquela $e$ assim como eles estavam cegos por causa da igreja hoje as pessoas estão cegas pelo dinheiro que pode ser o novo Deus delas.

Para construir seu argumento a aluna se reporta a conceitos históricos como "feudalismo" e "capitalismo" de forma comparativa, destacando modos de poder diferentes: a "cegueira" frente a Deus, possivelmente referindo-se à concepção teocêntrica e o domínio da Igreja na Idade Média, em relação à concepção atual em que domina uma visão capitalista. Sobre o capitalismo, tece considerações importantes, reportando à exploração, à dificuldade da luta contra seus efeitos perversos que "amarram", o fato de que por isso mesmo o grafite "incomoda" certas pessoas. A aluna constrói uma crítica com o que sabe sobre história, pois se utiliza de conhecimentos históricos trabalhados com a professora no ano anterior e elementos da realidade vivida, já que sempre passa pelo lugar onde está o grafite.

Algo que não se incluiu nas informações do jogo é que esse grafite é uma leitura do poema de Carlos Drummond de Andrade como mesmo título, "A máquina do tempo", pertencente ao livro Claro enigma e refere-se, resumidamente, ao sistema cósmico, ao modo de como o mundo funciona e a tudo o que ele rege e congrega. No caso, a aluna efetuou uma abordagem pertinente ao entender que o grafite apresenta um modo de funcionamento do mundo capitalista.

\section{Os desdobramentos da prática do game Pokémon Go: continuar aprendendo}

O conhecimento histórico "serve" para dar conta da vida prática no sentido de orientação existencial. Os interesses (primeira etapa) e as funções orientadoras (quinta e última etapa) da matriz disciplinar configuram o "início" e o "final" de um movimento, mas esse movimento nunca acaba. As necessidades sociais, as carências de orientação impulsionaram a construção do conhecimento histórico e este conhecimento "volta" para a mesma vida prática, de modo a se enriquecer as reflexões e as intencionalidades. Se forem empreendidas perguntas e respostas nesta direção, o passado pode ser "apropriado produtivamente" e então, "se tornar um fator de determinação cultural da vida prática" (Rüsen, 2010, p. 44). A quinta etapa, denominada "Funções", abarca este "retorno" para vida prática e o processo da construção do conhecimento pode recomeçar conforme as novas problemáticas que se impõem. 
O objetivo sempre foi fazer com que os alunos, após a atividade, continuassem refletindo, com mais cuidado ou crítica, sobre o espaço onde habitam, vivem, pensam. Ou seja, que sempre empreendam o movimento da matriz disciplinar de Rüsen. Queríamos que esses alunos prestassem atenção à história que a cidade conta.

A história, em Maringá, passa por outros PokéStops (lugares, objetos e imagens) que não inserimos aqui, por não terem sido descritos pelos alunos na experiência didática em questão. Entretanto, embora nenhum aluno tenha escrito sobre o PokéStops dos museus, passaram a ter conhecimento que existem: o Museu da Bacia do Paraná e o Laboratório de História e Etnografia Indígena, localizados na UEM; o Centro de Documentação Histórica, que fica nas dependências do Teatro Calil Haddad; o Museu da Cocamar, localizado no complexo dessa cooperativa; o Memorial Kimura, que fica na fazenda que pertenceu a família Kimura; e o Museu UniCesumar. Este último chama a atenção dos estudantes por ter cenários sobre o início da formação de Maringá: "A Tulha", uma construção feita com a madeira de demolição de um antigo armazém de café, cuja finalidade é remeter o visitante ao período áureo da cafeicultura da região, que foi a base econômica do início da colonização dessa região; a "Casa do Pioneiro" é uma residência de madeira construída em 1953 na região conhecida como Maringá Velho. Ela foi transplantada para o campus sede do Museu e serve para demonstrar como era o cotidiano dos chamados "pioneiros".

Na mesma linha e direção, um painel de Poty Lazzarotto no Teatro Calil Haddad, localizado no Shopping Cidade de Maringá, retrata o cotidiano da cidade em sua formação: a Catedral Nossa Senhora da Glória; o trabalho; um cancioneiro talvez cantando a música que alguns dizem que deu o nome à cidade, etc. O trabalhador, além do "pioneiro", é retratado em vários pontos da cidade: neste painel; no Museu da UniCesumar supracitado; no Painel do Café; no Painel em Alto Relevo também de Poty Lazzarotto, localizado num hipermercado da cidade; e no Painel Histórico Artístico do Colégio Santa Cruz Éder Portalha ${ }^{12}$. Alguns pontos edificam o trabalhador: Monumento ao Corretor de Imóveis, na Praça Raposo Tavares; Estátua do Construtor na entrada da Loja Maçônica; e a rua já citada, Agrimensor Nelson de Souza Figueiredo.

Os alunos se espantaram ao ver que o prédio da Companhia Melhoramentos Norte do Paraná abriga atualmente uma loja popular. Da mesma forma que o jogo foi utilizado para ter acesso aos PokéStops da cidade, os alunos fizeram uma pesquisa inversa: pesquisaram na internet quais seriam os patrimônios históricos da cidade, para depois verificar se havia PokésStops sobre os mesmos. Foi assim que souberam do Painel do Café, produzido em azulejos pelo artista Waldemar Mora, que apresenta uma cena de colheita de café, instalado em 
1956 no Bar Colúmbia, que era ponto de encontro de corretores, cerealistas e políticos ${ }^{13}$. Descobriram outro Painel produzido pelo mesmo artista, mas que não foi PokéStop por estar em uma residência da cidade: o painel "Colheita da Laranja".

O Monumento do Eixo; a estátua "Wooden Sculpture" (UEM); a escultura em madeira "O Imigrante" (UEM); o "Monumento do Centenário da Imigração Japonesa no Brasil" (Parque Japão), entre outros, considerados ou não como patrimônio histórico-cultural, foram discutidos posteriormente como locais que contam uma história.

Foi possível perceber pela escrita, apesar de alguns alunos terem uma espécie de aversão a lugares como o Teatro Cine Plaza e o Templo Budista, que, em geral, os alunos caminharam pela cidade observando criticamente o que ela nos conta, lembraram de conteúdos históricos adquiridos pela escolaridade, perguntaram às pessoas quando não sabiam, se interessaram em pesquisar outros PokéStops e, sobretudo, perceberam que a cidade privilegia um tipo de história mais tradicional, com a edificação dos chamados pioneiros, sem que estejam muito presentes grupos como os indígenas, os negros $e$ as mulheres. No entanto, reconheceram que os trabalhadores da roça dos tempos de colonização aparecem em diversos lugares.

Podemos dizer, para concluir este texto, que houve a construção do conhecimento histórico em relação à cidade, mas também uma compreensão sobre como se constrói esse conhecimento, através da análise das fontes históricas presentes na cidade. É preciso ainda levar em conta que Maringá passou a ser melhor compreendida, mais problematizada, mais internalizada como lugar que faz jus ao nosso afeto.

\section{Referências}

ANDRADE, Paulo Deporte; COSTA, Marisa Vorraber. Usos e possibilidades do conceito de pedagogias culturais nas pesquisas em estudos culturais em educação. Textura, v. 17, n. 34, 2015.

APPLE, Michael W. Ideologia e currículo. Trad. de Carlos Eduardo Ferreira de Carvalho. São Paulo: Brasiliense, 1982.

BARCA, Isabel. Aula Oficina: do Projeto à Avaliação. Para uma educação de qualidade: Atas da Quarta Jornada de Educą̧ão Histórica. Braga, Centro de Investigação em Educação (CIED)/ Instituto de Educação e Psicologia, Universidade do Minho, Portugal, 2004.

BARROS, José D’Assunção. Cidade e História. 2 ed. Petrópolis: Vozes, 2012.

BARTHES, R. Semiótica e urbanismo. In: A aventura semiológica. São Paulo: Martins Fontes, 1985. 
BERNSTEIN, Basil. Classes e pedagogia: visível e invisível. Cadernos de Pesquisa, n. 49, maio 1984, p. 36-42.

CAINELLI, Marlene; TUMA, Magda Madalena. História e memória na construção do pensamento histórico: uma investigação em Educação Histórica. Revista HISTEDBR online, Campinas, n. 34, 2009, p. 211-222.

CAMPOS, Márcia de Borba; GIRAFFA, Lúcia Maria Martins. Do pó de giz ao byte: uma reflexão acerca do uso de tecnologias na sala de aula. Caderno marista de tecnologia educacionai. Brasília: UMBRASIL, v.1, 2011, p. $7-18$.

CASSOL, Francielle M.; CAIMI, Flávia E. Pesquisando sítios arqueológicos: História e patrimônio na sala de aula. Revista EntreVer, v. 1, 2012, p. 278-295.

COLL, Cesar; MAURI, Teresa; ONRUBIA, Javier. A incorporação das tecnologias da informação e da comunicação na educação: do projeto técnico-pedagógico às práticas de uso. In: COLL, César; MONEREO, Carles. Psicologia da educação virtual: aprender e ensinar com as tecnologias da informação e da comunicação. Porto Alegre: Artmed, 2010.

COSTA, Marcela Albaine Farias da. Ensino de história e games. Dimensões práticas em sala de aula. Curitiba, PR: Appris, 2017.

CRIVELLO, Marylene. Usages publics et mises en spectacle de l'histoire dans la France contemporaine: contrastes mémoriels. Cahier d’histoire immediate. Les Usages du Passé. n. 43, 2013, p. 7-20.

DIAS, Reginaldo Benedito. A história além das placas. Os nomes de ruas de Maringá (PR) e a memória histórica. História E̊ Ensino, vol. 6, 2000, p. 103-120.

EDWARDS, Verónica. Os sujeitos no universo da escola: um estudo etnográfico no ensino primário. Trad. Josely Vianna Baptista. São Paulo: Ática, 1997.

FARDO, Marcelo. A gamificação aplicada em ambientes de aprendizagem. Renote - novas tecnologias da educação. V.11, n.1, 2013, p. 1-9.

FUNARI, Pedro Paulo; PELEGRINI, Sandra C. A. Patrimônio Histórico Culturai. Rio de Janeiro: Jorge Zahar, 2006.

GOODSON, Ivor. La construcción social del curriculum: possibilidade y âmbitos de investigación de la historia del curriculum. Revista de Educación, v. 1, n. 295, 1991, p. 7-37. 
HORTA, Maria de Lourdes Parreiras; GRUNBERG, Evelina; MONTEIRO, Adriane Queiroz. Guia básico de educą̧ão patrimoniai. Brasília: Instituto do Patrimônio Histórico e Artístico Nacional, Museu Imperial, 1999.

HUIZINGA, J. Homo ludens: o jogo como elemento da cultura. Perspectiva: São Paulo, 1999.

LEE, Peter. Em direção a um conceito de literacia histórica. Educar em Revista. Especial. Dossiê: Educação Histórica, 2006.

LEFEBRE Fernando; LEFEBRE, Ana Maria. Pesquisa e representação sociai: um enfoque qualitativo. Brasília: Liber Livro, 2012.

MIRANDA, Sonia Regina; BLANCH, Joan P. Cidade, Memória e Educação: conceitos para provocar sentidos no vivido. In: MIRANDA, Sonia Regina; SIMAN, Lana Mara Castro (orgs.). Cidade, memória e educação. Juiz de Fora: Editora UFJF, 2013.

MORAN, José Manuel. Ensino e Aprendizagem Inovadores com Tecnologias Audiovisuais e Telemáticas. In: MORAN, José Manuel; MASETTO, Marcos e BEHRENS, Marilda (orgs.). Novas Tecnologias e mediação pedagógica. São Paulo: Editora Papirus, 2010, p. 11-66.

NORA, Pierre. Entre história e memória: a problemática dos lugares. Revista Projeto História. São Paulo, v. 10, 1993, p. 7-28.

PETRY, Luís Carlos. O conceito ontológico de jogo. In: ALVES, Lynn; CONTINHO, Isa de Jesus (orgs.). Jogos digitais e aprendizagem. Fundamentos para uma prática baseada em evidências. Campinas, SP: Papirus, 2016, p. 17-42.

RÜSEN, Jörn. O Desenvolvimento da competência narrativa na aprendizagem histórica: uma hipótese ontogenética relativa à consciência moral. In: SCHMIDT, Maria; BARCA, Isabel; MARTINS, Estevão (orgs.). Jörn Rüsen e o Ensino de História. Curitiba: Ed. UFPR, 2010, p. 51-78.

RÜSEN, Jörn. Razão histórica. Teoria da história: os fundamentos da ciência histórica. Trad. Estevão de Rezende Martins. Brasília: Editora Universidade de Brasília. 2001.

SILVA, Armando. Imaginários urbanos. São Paulo: Perspectiva, 2011.

STRAUBHAAR, Joseph; LAROSE, Robert. Comunicação, mídia e tecnologia. São Paulo: Pioneira Thomson Learning, 2004.

TRIPP, David. Pesquisa-ação: uma introdução metodológica. Educação e Pesquisa, v. 31, n. 3, 2005, p. 443-466. 
TUTIAUX-GUILLON, Nicole. O paradoxo francês: cultura histórica significativa e didática da história incerta. Educação e Realidade, v. 36, n. 1, 2011 p. 15-37.

ZANIRATO, Sílvia Helena. Usos sociais do patrimônio cultural e natural. Patrimônio e Memória, v. 5, n. 1, 2009, p. 137-152.

\footnotetext{
${ }^{1}$ Disponível em: https://pt.wikipedia.org/wiki/Cidade. Acesso em 14 de fevereiro de 2018.

${ }^{2}$ Disponível em:
}

https://www.google.com.br/search?q=cidadebsignificado\&oq = cidadebsignificado\&aqs=chrome..69i57j015.3549j1j4\& sourceid =chrome\&ie $=$ UTF-8. Acesso em 01 de Março de 2018.

${ }^{3}$ Esta pesquisa segue rigorosamente a Resolução CNE no 466/2012 (Ética na Pesquisa com seres humanos), em especial: "II.5 - consentimento livre e esclarecido - anuência do participante da pesquisa e/ou de seu representante legal, livre de vícios (simulação, fraude ou erro), dependência, subordinação ou intimidação, após esclarecimento completo e pormenorizado sobre a natureza da pesquisa, seus objetivos, métodos, benefícios previstos, potenciais riscos e o incômodo que esta possa acarretar"; "II.17 - protocolo de pesquisa - conjunto de documentos contemplando a descrição da pesquisa em seus aspectos fundamentais e as informações relativas ao participante da pesquisa, à qualificação dos pesquisadores e a todas as instâncias responsáveis"; "II.23 - Termo de Consentimento Livre e Esclarecido - TCLE - documento no qual é explicitado o consentimento livre e esclarecido do participante e/ou de seu responsável legal, de forma escrita, devendo conter todas as informações necessárias, em linguagem clara e objetiva, de fácil entendimento, para o mais completo esclarecimento sobre a pesquisa a qual se propõe participar" e "II.24 Termo de Assentimento - documento elaborado em linguagem acessivel para os menores ou para os legalmente incapazes, por meio do qual, após os participantes da pesquisa serem devidamente esclarecidos, explicitarão sua anuência em participar da pesquisa, sem prejuízo do consentimento de seus responsáveis legais".

${ }^{4}$ Há uma lei no estado do Paraná, onde aplicamos essa pesquisa, que proíbe o uso dos celulares e equipamentos eletrônicos que não sejam para fins didáticos. Ver: Lei 18118, de 24 de Junho de 2014. Disponível em: http://www.legislacao.pr.gov.br/lesgilacao/listarAtosAno.do?action=exibir\&codAto=123359. (Acesso em 22 de maio de 2017).

${ }^{5}$ De acordo com o Art. 216 da Constituição Federal Brasileira constituem patrimônio cultural brasileiro: "[...] os bens de natureza material e imaterial, tomados individualmente ou em conjunto, portadores de referência à identidade, à ação, à memória dos diferentes grupos formadores da sociedade brasileira. São eles: As formas de expressão; Os modos de criar, fazer e viver; As criações científicas, artísticas e tecnológicas; As obras, objetos, documentos, edificações e demais espaços destinados às manifestações artístico-culturais; Os conjuntos urbanos e sítios de valor histórico, paisagístico, artístico, arqueológico, paleontológico, ecológico e científico". Disponível em: http://www.cultura.al.gov.br/politicas-e-acoes/patrimonio-cultural/principal/textos/patrimonio-cultural-o-que-e. Acesso em 05 de dez. de 2018.

${ }^{6}$ É uma cidade classificada como sendo de porte médio-grande, a terceira maior do Estado e a sétima mais populosa da região sul do Brasil. Dista 426 quilômetros da capital Curitiba. De acordo com o Instituto Brasileiro de Geografia e Estatística (IBGE) de 2017, Maringá possui uma população de 406.693 habitantes e sua Região Metropolitana conta com 754.570 habitantes.

${ }^{7}$ GPS é a sigla para Global Positioning System, que em português significa Sistema de Posicionamento Global, e consiste em uma tecnologia de localização geográfica por satélite.

${ }^{8}$ A nosso ver, tais acidentes ou furtos não podem ser imputados ao jogo em si, mas ao uso inconsequente que se faz do mesmo. Esta divergência de opiniões sempre acompanha a emergência de uma nova tecnologia de comunicação, desde o livro, até a TV e, agora, a internet.

${ }^{9}$ Outros locais com PokéStops e Ginasiums em Maringá: Parque do Ingá (ao redor e vários dentro do parque); Paço Municipal, Mural Artístico, Mercadão, PUC, Colégio Paraná, Ginásio Willie Davids, Secretaria da Saúde (estátua Zé Gotinha), Igreja Adventista do Sétimo Dia, Centro Administrativo Nagib Neme, Monumento de Declaração de Cidades Irmãs, Biblioteca Municipal, Centro de Convivência Comunitária, Comemoração Centenário da ONU, Estátua de Nossa Senhora da Glória, Mural do Fórum, Linguarudo (arte de rua no Jardim Universitário). A Universidade Estadual de Maringá tem vários PokéStops, por exemplo: Grafite Medusa no Bloco G-34; Grafite John Lennon; Wooden Sculpture (estátua esculpida em madeira; O Imigrante (escultura em madeira);

${ }^{10}$ Optamos por manter a forma como o aluno escreveu. Estas narrativas estarão em itálico.

${ }^{11}$ Reginaldo Benedito Dias (2000) considera que há bairros em que as ruas receberam nomes de estados brasileiros, capitais e importantes cidades latino-americanas, árvores e plantas, rios, pedras preciosas, aves, planetas e astros, cantores, etc. Outros com nomes ligados à história, destacando Proclamação da República, Independência etc. 
${ }^{12}$ Este painel resume o que se quer contar sobre a colonização da região e da cidade: a derrubada da mata; pessoas com enxadas na mão, junto à carroça de boi, colhendo ou plantando café, cortando madeira, usando o pilão, portando espingarda, trabalhando na forja; charretes e moradias; a construção da Capela Santa Cruz. Por fim, neste painel, a cidade "evolui" chegando na construção da Catedral Nossa Senhora da Glória e no primeiro colégio particular (onde se encontra o painel). Isso mostra outra representação que se justapõe à ideia de cidade moderna, progressista, empreendedora, isto é, a ideia de povoar que a cidade se deu com base em muito trabalho.

${ }^{13}$ Até pouco tempo, encontrava-se nos fundos de uma loja, mas foi levado para restauração em São Carlos (SP) - e por isso não era um PokéStop - e será então, em 2018, enviado para o aeroporto da cidade. 